\title{
Human body capacitance: static or dynamic concept? [ESD]
}

\author{
Jonassen, Niels M
}

Published in:

Electrical Overstress/Electrostatic Discharge Symposium Proceedings, 1998

Link to article, DOI:

10.1109/EOSESD.1998.737028

Publication date:

1998

Document Version

Publisher's PDF, also known as Version of record

Link back to DTU Orbit

Citation (APA):

Jonassen, N. M. (1998). Human body capacitance: static or dynamic concept? [ESD]. In Electrical Overstress/Electrostatic Discharge Symposium Proceedings, 1998 (pp. 111-117). IEEE.

https://doi.org/10.1109/EOSESD.1998.737028

\section{General rights}

Copyright and moral rights for the publications made accessible in the public portal are retained by the authors and/or other copyright owners and it is a condition of accessing publications that users recognise and abide by the legal requirements associated with these rights.

- Users may download and print one copy of any publication from the public portal for the purpose of private study or research.

- You may not further distribute the material or use it for any profit-making activity or commercial gain

- You may freely distribute the URL identifying the publication in the public portal

If you believe that this document breaches copyright please contact us providing details, and we will remove access to the work immediately and investigate your claim 


\title{
HUMAN BODY CAPACITANCE STATIC OR DYNAMIC CONCEPT ?
}

\author{
Niels Jonassen \\ Department of Physics, Bldg. 307 \\ Technical University of Denmark \\ 2800 Lyngby, Denmark \\ phone: +45 45253127 , fax: +45 45932766 , e-mail: mr.static@scientist.com
}

\begin{abstract}
A standing, human body insulated from ground by footwear and/or floor covering is in principle an insulated conductor and has, as such, a capacitance, i.e. the ability to store a charge and possibly discharge the stored energy in a spark discharge.

In the buman body model the buman body capacitance (HBC) is traditionally chosen as $100 \mathrm{pF}$. However, a simple geometric model seems to suggest considerably higher values.

A series of experiments, where the capacitance of standing persons were determined for various combinations of footwear and floor coverings, gave values in the order of $100-150 \mathrm{pF}$, when the capacitance was determined by an AC-bridge measurement, but $200-400 \mathrm{pF}$, when the traditional static charge-sharing metbod was used.

Further experiments indicate that the two methods give the same result, when the electric flux is well located in a dielectric other than air, but that the static method leads to higher values when a substantial part of the flux extends itself through badly defined stray fields.

Since the concept of human body capacitance is normally used in a static (electric) context, it is suggested that the $H B C$ be determined by a static method.

No theoretical explanation of the observed differences is presently at hand.
\end{abstract}

\section{INTRODUC'TION}

A person, insulated from ground by footwear and/or floor covering, is electrically characterized by her body and grounding resistance and her capacitance. While the concept of body- and grounding resistance is easy to visualize as primarily the resistance along the surface of the body and the resistance through the shoes in series with the floor, the capacitance is a somewhat more elusive concept.

The capacitance (with respect to ground) $C$ of an insulated conductor is defined by the equation:

$\mathrm{q}=\mathrm{CV}$

where $\mathrm{V}$ is the voltage of the conductor with respect to ground when the conductor carries a charge $\mathrm{q}$.

The voltage $\mathrm{V}$ of the conductor is defined by

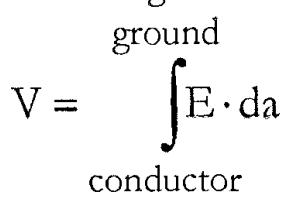

where $\mathrm{E}$ is the field strength along any path from the conductor to grounded surroundings.

The relationship between charge $q$ and field strength $\mathrm{E}$ is fundamentally determined by the E-flux as given by Gauss' theorem (or sentence):

$$
\int_{S} \varepsilon E \cdot d S=\int_{S} D \cdot d S=q
$$

where $S$ is a surface enclosing the charged body and $\varepsilon$ is the permittivity of the medium at the site of $S$ and $D$ is the dielectric displacement (or electric flux density).

The distribution of the flux and consequently the magnitude of the capacitance is thus a question of geometry (and permittivity).

It is probably not possible to accurately model the distribution of flux around a charged person in a given environment and thus also not possible to accurately predict the capacitance. 


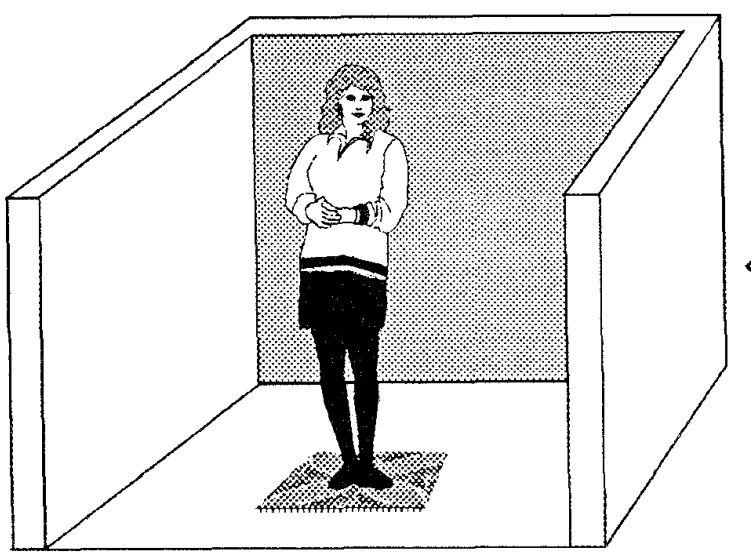

Fig. 1.

Several approaches have been suggested, often approximating the capacitance of a standing person

with that of a free sphere in parallel with a parallel plate capacitor made up of the feet in a given distance from a conductive layer in or under the floor $[1,2]$.

To this author the sphere-approximation does not seem obvious (and also somewhat unflattering for most people).

Instead we choose to approximate (only as far as the capacitance is concerned) a person in a room, Fig. 1, with a cylinder capacitor in parallel with a parallel plate capacitor.

$\mathrm{C}_{\text {person }}=\mathrm{C}_{\text {cylinder }}+\mathrm{C}_{\text {plate }}$

The cylinder capacitor is made up of the "vertical" surface of the person and the walls of the room with the capacitance:

$$
\mathrm{C}_{\text {cylinder }}=\frac{2 \pi \varepsilon h}{\ln \frac{\mathrm{R}}{\mathrm{r}}}
$$

where $h$ is the height of the cylinder (person) $\approx$ $1.7 \mathrm{~m}, \mathrm{R}$ the average distance to the walls $\approx 2 \mathrm{~m}$, $r$ the "radius" of the person, $\approx 0.2 \mathrm{~m}$ and $\varepsilon=\varepsilon_{\circ}$ $=8.85 \cdot 10^{-12} \mathrm{~F} \cdot \mathrm{m}^{-1}$ the permittivity of vacuum (and air).

Introducing these figures in eq. (5) we find:
The parallel plate capacitor is made up of the feet and the nearest conductive layer in the floor with the capacitance:

$\mathrm{C}_{\text {plate }}=\varepsilon_{0} \varepsilon_{\mathrm{r}} \frac{\mathrm{A}}{\mathrm{t}}$

where $\varepsilon_{\mathrm{r}}$ is the relative permittivity of the shoe soles and floor material $\approx 4-5$, A the area of the shoe soles $\approx 200-300 \mathrm{~cm}^{2}$ and $\mathrm{t}$ the thickness of the insulating layer in the soles and the floor $\approx 5$ $10 \mathrm{~mm}$.

Introducing these figures in eq. (6) we find

$\mathrm{C}_{\text {plate }} \approx 70-260 \mathrm{pF}$.

If these figures represent the real world we should thus expect the total capacitance to have the value

$\mathrm{C}_{\text {person }}=100-300 \mathrm{pF}$.

It should be noted that although similar ranges have been reported in the literature [1,3] a value as low as $100 \mathrm{pF}$ has been chosen as a standard in Human Body Model-testing of semiconductor components and devices.

The purpose of this paper is to compare the results of measurements of the human body capacitance by different methods and evaluate what method gives the result most relevant in a static electric context.

$\mathrm{C}_{\text {cylinder }} \approx 40 \mathrm{pF}$ 


\section{METHODS OF MEASUREMENT}

The capacitance with respect to ground of a human body can be measured in two ways.

\section{Charge-sharing method}

A capacitor with the known capacitance $\mathrm{C}_{\mathrm{N}}$ has one terminal connected to ground and the other to a static voltmeter, Fig. 2.
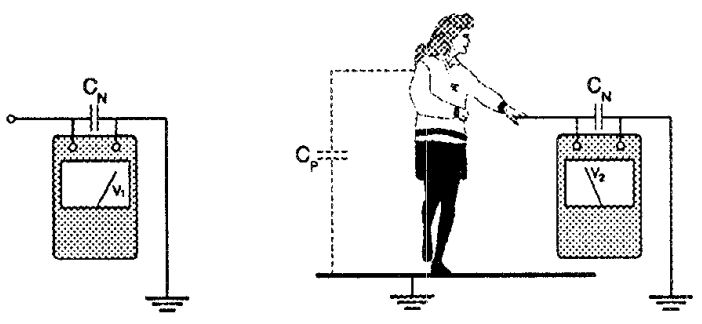

Fig. 2

The capacitor is charged to a voltage $V_{1}$. If the voltage drops to $V_{2}$ when the uncharged person touches the capacitor, the capacitance of the person, $C_{P}$ is given by:

$$
C_{P}=C_{N} \frac{V_{1}-V_{2}}{V_{2}}
$$

\section{AC-measurement of body capacitance}

Most people working with circuits will consider a capacitor as an AC-component exhibiting a reactance:

$$
\mathrm{X}_{\mathrm{C}}=\frac{1}{2 \pi \nu \mathrm{C}}
$$

where $v$ is the frequency of the current through the capacitor.

The common AC-method of determining a capacitance is by balancing in a so-called bridge the unknown capacitance relative to a known capacitance by a corresponding (easily measurable) ratio between resistors.

\section{Body- and grounding resistance}

As mentioned a person's electrical characteristics also include the body- and the grounding resistance, Fig. 3.

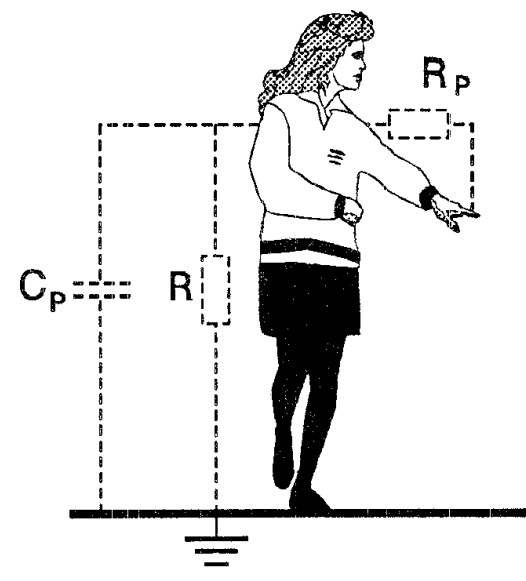

Fig. 3

The body resistance, $R_{p}$, is the resistance from the primary location of a charge on the person to the point of discharge. For a standing person this will normally be from the underside of her feet to a fingertip.

Although this resistance may vary somewhat from person to person a representative value seems to be about $1 \mathrm{k} \Omega$.

The grounding resistance, $R$, i.e. the resistance through the series of shoes and floor, on the other hand, may vary from a few ohm to $10^{15}$ ohm or higher.

Neither of the two resistances have any influence on the value of $C_{p}$, determined by a correctly performed $\mathrm{AC}$-measurement.

If the capacitance is determined by the static charge-sharing method, the voltage $V_{2}$ depends on how long the person is in contact with the voltmeter. If the contact time is short compared to $R_{p}$, the drop in voltage caused by decay during contact is negligible.

Assuming a contact time of $<0.1 \mathrm{~s}$ and $\mathrm{C}_{\mathrm{p}} \sim 200$ $\mathrm{pF}$ the method is good for $\mathrm{R}>\sim 5 \cdot 10^{10} \Omega$.

For lower values of $\mathrm{R}$ the method is still good if the person is placed on a thin sheet of wellinsulating plastic, which will not change her capacitance to a measurable degree. 
Comparison between the charge-sharing and the AC-bridge method.

The two methods of determining capacitances were compared experimentally by measuring a series of capacitors in the range from $10 \mathrm{pF}$ to $10 \mathrm{nF}$. The capacitors were various commercially available, commonly used circuit components.

The charge-sharing method was performed using a Keithley 620 electrometer and in most cases using a starting voltage of about one hundred volt. The measurements yielded values with a standard deviation on a single determination of a few per cent and well within the guaranteed range for the component tested.
The AC-method was done with a conventional AC-bridge at a frequency of $1000 \mathrm{~Hz}$. The values were again within the guaranteed range, however the uncertainty of reading the values were greater than the accuracy of the measurement.

In Table 1 is shown an example of a set of measurements of the Human Body Capacitance for a combination of polymeric soles and a linoleum floor covering.

The grounding resistance of the person was measured by a Keithley 620 electrometer.

It appears that there is a difference of $98 \mathrm{pF}$ (or about $58 \%$ of the $\mathrm{AC}$-value) between the two determinations of the $H B C$.

\section{Date Aug 5, 1997.}

Shoes: polymeric soles, Floor: linoleum, Ground resistance: 5-6 T $\Omega$

Human Body Capacitance $(A C): 170 \mathrm{pF}$, (reading uncertainty $\sim 10 \%$ )

Human Body Capacitance (charge sharing), meter capacitance, $\mathrm{C}_{\mathrm{N}}=1000 \mathrm{pF}$

\begin{tabular}{||c|c|c|c|c|c|c|c|c|c|c||}
\hline \hline $\begin{array}{c}\mathrm{V}_{1} \\
\text { volt }\end{array}$ & 98 & 75 & 58 & 45 & 35 & 98 & 75 & 59.5 & 47 & 37 \\
\hline $\begin{array}{c}\mathrm{V}_{2} \\
\text { volt }\end{array}$ & 75 & 58 & 45 & 35 & 28 & 75 & 59.5 & 47 & 37 & 28.5 \\
\hline $\begin{array}{c}\mathrm{C}_{\mathrm{p}} \\
\mathrm{pF}\end{array}$ & 234 & 293 & 289 & 285 & 250 & 234 & 260 & 266 & 270 & 298 \\
\hline
\end{tabular}

Table 1

Comparison of $H B C$ determined by the $A C$ - and charge sharing measurements

\begin{tabular}{|c|c|c|c|c||}
\hline shoes & floor & $\begin{array}{c}\text { resistance } \\
\mathrm{T} \Omega\end{array}$ & $\begin{array}{c}\text { HBC, AC } \\
\mathrm{pF}\end{array}$ & $\begin{array}{c}\text { HBC, ch-sh } \\
\mathrm{pF}\end{array}$ \\
\hline poly I & linoleum & $\sim 5$ & 170 & 268 \\
\hline poly II & linoleum & $\sim 4$ & 160 & 235 \\
\hline no shoes & linoleum & $\sim 2$ & 250 & 614 \\
\hline poly I & asphalt & $\sim 1$ & 110 & 216 \\
\hline poly II & asphalt & $\sim 1$ & 110 & 212 \\
\hline no shoes & asphalt & $\sim 0.3$ & 185 & 385 \\
\hline leather & asphalt & $\sim 0.2$ & 115 & 254 \\
\hline leather & plastic on metal & $\sim 0.05$ & 900 & 2680 \\
\hline no shoes & plastic on metal & $\sim 0.3$ & 2850 & 5580 \\
\hline
\end{tabular}

Table 2

$H B C$ for varions combinations of shoes and floor determined by the $A C$ - and the charge sharing methods 
In order to see if this difference between the results of the two methods is consistent, a series of measurement of the $H B C$ with other combinations of shoes and floor coverings were performed with the results shown in Table 2.

The shoes marked poly I and poly II were shoes with different types of polymeric soles. With the measurements marked leather/plastic on metal and no shoes/plastic on metal the person was standing (with leather soled shoes or with no shoes) on a grounded metal plate covered by a thin sheet of plastic.

It appears that the charge sharing method yields results, which are from about $50 \%$ to $200 \%$ higher than do the AC-method.

Since initial measurements indicated good agreement between the determinations of the capacitance of circuit capacitors with well-defined capacitances determined by the two methods, it was decided to investigate how the geometrical properties of a capacitive item influence the value of the capacitance as determined by the AC-and the charge-sharing method.

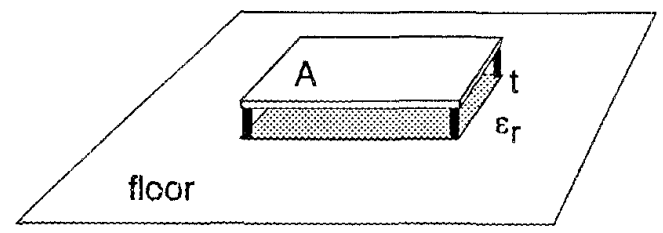

Fig.4

To this end, the capacitive systems shown in Figs. 4 and 5 were used.

Fig. 4 shows a capacitor consisting of a metal plate with the area $A$ separated from a grounded metal floor plane by a distance of $t$. This interspace may be air or filled by a dielectric with the relative permittivity $\varepsilon_{\mathrm{r}}$. In the set-up shown in Fig. 5, a metallic cylinder with the outer radius $\mathrm{r}$ and height $\mathrm{h}$ is placed on the metal plate. The capacitances of the two types of systems may then be estimated from eqs. (4), (5) and (6).
In Table 3 are shown the results of calculations and measurements of the capacitances of a series of capacitive systems as shown in Figs. 4 and 5 . The results in Table 3 seem to indicate, like the initial measurements of the capacitance of commercially available capacitors, that the AC-bridge method and the charge-sharing method yield the same result when dealing with capacitive systems where the electric flux is largely confined to a well-defined dielectric region.

In column 1 of Table 3 we have a parallel plate capacitor with air as the dielectric. In this case we should expect a substantial stray field at the edges of the plates leading to a higher capacitance than what can be calculated from eq. (6). As appears from the table, this is what we find with both methods of measuring the capacitance, with the charge-sharing method yielding the highest value.

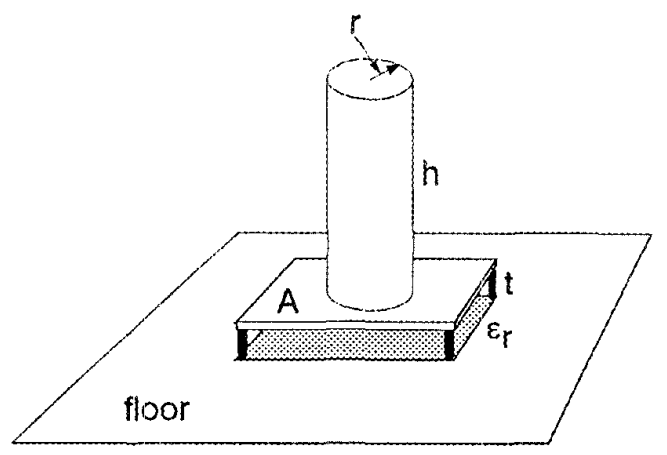

Fig. 5

In column 2 and 3 we are dealing with a parallel plate capacitor where the major part of the field determining the capacitance is extending itself through a dielectric, and in these cases the two methods give identical results, and agree with the theoretical value as calculated from eq. (6).

In column 4 and 5 we are considering a capacitor corresponding to the human body model suggested in Fig. 1 (and Fig. 5).

The general result is again that the capacitance measured by the AC-method is lower than when measured by the static charge-sharing method. 


\begin{tabular}{||c|c|c|c|c|c|}
\hline & 1 & 2 & 3 & 4 & 5 \\
\hline Fig. & 4 & 4 & 4 & 5 & 5 \\
\hline $\begin{array}{c}\text { plate area, } \\
\mathrm{A}, \mathrm{m}^{2}\end{array}$ & $0.20 \times 0.28$ & $0.20 \times 0.28$ & $0.20 \times 0.28$ & $0.20 \times 0.28$ & $0.20 \times 0.28$ \\
\hline $\begin{array}{c}\text { plate distance } \\
\mathrm{t}, \mathrm{m}\end{array}$ & 0.02 & 0.02 & 0.007 & 0.02 & 0.007 \\
\hline $\begin{array}{c}\text { rel. permittivity, } \\
\varepsilon_{\mathrm{r}}\end{array}$ & 1 & 4 & 3.4 & 4 & 3.4 \\
\hline $\begin{array}{c}\text { cylinder height, } \\
\mathrm{h}, \mathrm{m}\end{array}$ & & & & 1.53 & 1.53 \\
\hline $\begin{array}{c}\text { cylinder } \\
\text { radius, } \mathrm{r}, \mathrm{m}\end{array}$ & 25 & 99 & 240 & 0.055 & 0.055 \\
\hline $\begin{array}{c}\mathrm{C}_{\text {theorev }} \mathrm{pF} \\
\mathrm{C}_{\mathrm{Ac}, \mathrm{pF}}\end{array}$ & 47 & 100 & 235 & 123 & 263 \\
\hline $\mathrm{C}_{\mathrm{c}-\mathrm{s}, \mathrm{pF}}$ & 66 & 100 & 245 & 140 & 280 \\
\hline \hline
\end{tabular}

Table 3

\section{Comparison of theoretical capacitances of different capacitive systems and capacitances of the same systems measured by the $A C$-and charge-sharing methods}

\section{Discussion of results}

When an insulated conductor receives a charge it may cause two types of electrostatic effects: it may create a field possibly causing a breakdown, and/or it may dissipate a certain energy in its surroundings. Both of these effects are determined by the charge and the capacitance of the conductor. Although the capacitance is a geometric/permittive quantity, independent of whether or not the conductor is charged, the definition of the capacitance is the ratio between a charge and the resulting voltage of the conductor.

It therefore seems natural to determine the capacitance, which together with the charge is responsible for the electrostatic effects, by comparing the voltage of the charged conductor with the voltage when the conductor shares the same charge with a conductor with a known capacitance. And this is, as explained above, the charge-sharing method.

If an insulated conductor enters as a part of an AC-circuit, it may partly determine the impedance of the circuit contributing with a reactance:

$$
\mathrm{X}_{\mathrm{C}}=\frac{1}{2 \pi v \mathrm{C}}
$$

where $v$ is the frequency of the AC-current.

A capacitance determined by the static chargesharing method has the dimension of charge over voltage while a capacitance determined by an ACmeasurement has the (identical) dimension of time over resistance.

Hence it could be speculated that the results of charge-sharing measurements depemd on the staring voltage and that the AC-capacitance of an object with a badly defined stray field may be frequency dependent.

In order to check these speculations, a series of $H B C$ charge-sharing determinations were done at voltages up to $5 \mathrm{kV}$ (using a capacitive voltage divider).

Similarly, a make-shift capacitance bridge was put together and the $H B C$ was determined for frequencies from $100 \mathrm{~Hz}$ to $10 \mathrm{kHz}$.

No dependence of the capacitances measured on starting voltage or frequency could be detected. 


\section{Conclusion}

This paper has, for a rather limited range of objects, demonstrated that when we are dealing with systems with well-defined capacitances (i.e. the flux is well located) the static charge-sharing and the AC-methods of measuring capacitances yield comparable results.

When, however, the flux is more strayingly distributed, as is the case with an insulated human body, the measurements reported here indicate that the charge-sharing method always yield a higher value. No solid theoretical explanation for the difference can presently be offered.

\section{References}

1. McAteer, O.J., (1990) Electrostatic Discharge Control, McGraw-Hill, NY, p. 169-173

2. Seaver, A.E., (1997), ESA Annual Meeting, U. Georgia.

3. Dangelmayer, G.T., 1990, ESD Program Management, Van Nostrand Reinhold, NY, p. 37
Based on the results reported, it is suggested that when dealing with predicting electrostatic effects one should prefer an electrostatic method.

One could argue that the $\mathrm{AC}$-bridge method is easy and simple to employ.

This is correct.

Almost as simple and easy as the charge-sharing method. 